IRA-International Journal of Education \& Multidisciplinary Studies

ISSN 2455-2526; Vol.04, Issue 02 (2016)

Pg. no. 237-242

Institute of Research Advances

http://research-advances.org/index.php/IJEMS

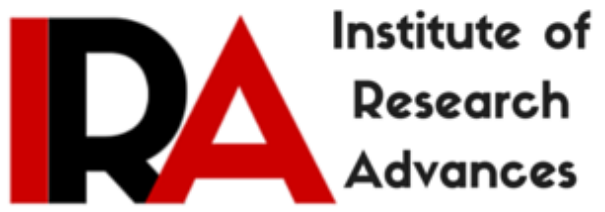

\title{
Geriatric and Psychiatric Mental Health Case Analysis: A Psychodynamic Perspective
}

Suk-hee Kim, (Ph.D., COI, MSW)

Department of Counseling, Social Work and Leadership

Northern Kentucky University, USA.

Type of Review: Peer Reviewed

DOI: http://dx.doi.org/10.21013/jems.v4.n2.p2

\section{How to cite this paper:}

Kim, S. (2016). Geriatric and Psychiatric Mental Health Case Analysis: A Psychodynamic Perspective. IRA International Journal of Education and

Multidisciplinary Studies (ISSN 2455-2526), 4(2), 237-242.

doi:http://dx.doi.org/10.21013/jems.v4.n2.p2

(C) Institute of Research Advances

(cc) EY-NC

This work is licensed under a Creative Commons Attribution-Non Commercial 4.0 International License subject to proper citation to the publication source of the work.

Disclaimer: The scholarly papers as reviewed and published by the Institute of Research Advances (IRA) are the views and opinions of their respective authors and are not the views or opinions of the IRA. The IRA disclaims of any harm or loss caused due to the published content to any party. 


\begin{abstract}
This article presents an approach to assess and intervene a geriatric and psychiatric mental health hospital client based on a psychodynamic perspective. Psychodynamic theory contributes the idea that social workers choose an approach that supports clients to replicate significant mental health aging experiences. The purpose of this study is to assess whether depressed geriatric clients would respond to psychodynamic assessment to their mental illness and, if so, whether the client respond also to the intervention. A 60-year-old Caucasian, single, and female entered the study. A case illustration is presented that demonstrates the application of psychodynamic approach.
\end{abstract}

Key words: Aging, Psychodynamic, Mental Health, Social Work, Assessment, Intervention

\title{
INTRODUCTION
}

The depressed elderly person's loss of self-esteem is a critical indication to dynamics. It implies that to maintain self-esteem individual must sustain neither losses nor disappointments. Freud concerns his work on depression on what was to become a structural paradigm (Beck, 2012). We often understand the ego is to unable to accept a loss or self-centered setback to pride. One part, later designated as the superego, then criticized the other. In terms of emotional change, this means that the individual (ego) cannot accept the loss or injury, feels weakened, devalued, and angry at the possibility of helplessness implied, and even turns the anger on the self. This anger is coercive, aimed on the one hand at restoring the loss, and provoking and punishing the self for being unable to do so on the other. Developmentally, self-important magnificence and childhood influence are at first related to safety and satisfaction. Selfesteem comes with the sense of being accepted, loved, and effective.

\section{Erikson's Developmental Stage}

There is a well-developed literature describing the process by which we all proceed through biologically included life-cycle changes (Beck, 2012). Though biologically induced, these processes are shaped by psychological, socioeconomic, and cultural forces. These dynamic, interacting processes have been conceptualized by Erikson as occurring in epigenetic stages of development. Each stage requires changes and redefinitions in relationships with significant others, negotiations with the external environment, and struggles with one's self-definitions and self-identity. In general, personal and environmental resources support or frustrate an individual's ability to develop a sense of mastery and competence.

According to Erikson, during the early years of a child's life we learn and achieve the qualities of trust, autonomy and initiative. In the first years of life, the child is totally dependent upon parents or caregivers. For trust to be developed, they have to be trust worthy and dependable. For autonomy and initiative to be accomplished, then they have to encourage and support such behaviors. Erickson identifies a potential perfect match, child is need to be nourished and parents' own specific needs for intimacy and caring (Beck, 2012).

The developmental cycle from birth to old age is not permanent or identical. A developmental stage takes place within the context of historical and societal realities. People born at a similar time experience common historical events. These common events affect the ways a particular generation experiences its developmental responsibilities. For example, the periods of war and peace, prosperity or depression, assimilation or acculturation deeply affect the opportunities and world views of different generations. 


\section{A GERIATRIC AND PSYCHIATRIC CASE ASSESSMENT, INTERVENTION AND ANALYSIS A Geriatric and Psychiatric Case Assessment}

Dianna was admitted to the Geriatric and Psychiatric hospital. Dianna is a 60-year-old single Caucasian female, and a Medicaid status client. The client was admitted for gait falls and dementia evaluation. The client was a department of mental health client and was one member of a rehabilitation program in the hospital. The client has had a psychiatric history since she was thirteen years old, which include such manifestations as delusions and irritability. When she was admitted to the hospital, she was timid, agitated, and suffering such mental illnesses as schizophrenia and delusions. The client also has the misfortune of being legally blind. However, she can see somewhat, and the degree of capability varies from time to time; thus she has poor eye contact as well.

The client has a long history of chronic non-progressive headaches, but the client's headaches have seen recent improvement. According to the client's testimony, "I'm so happy, I don't have headaches now...It's amazing...I can't believe it." At that time, she was taking Tylenol three times a day, dementia and headaches being treated together through her medication. Afterward, the client seemed very pleasant about the lack of headaches, and the social work intern responded saying 'that sounds very good for you and it is very pleasant to see your smile back.' These conditions, worsened by a long history of substance abuse, such as alcohol and cigarettes, pose a challenging case for any social worker.

The client also has a very poor family history, though it proves to be interesting. The client reported that she was apparently adopted from Okinawa and has two sisters, one approximately seventytwo, the other forty-five; there is also an eighty year-old brother. The client was supposedly married, and had given birth to three children-one boy and two girls. She is suffering under the belief that all of them were murdered.

Before the client came to the hospital, she lived in a group home, and the client had two friends in that place. Even so, she proves to be very isolated and timid. When describing her family and friends situation, Dianna was not willing to talk deeply about those issues, to the point of becoming very upset about mentioning any relationship around her at that time.

\section{Psychodynamic Assessment \\ Developmental and Relational Influences}

In working with Dianna, the social work intern was able to establish trust rather easily, and client and intern quickly developed a positive, strong relationship. The client expresses her thoughts and feelings a little by little in sessions. From a developmental perspective, the childhood stages of Erikson's theory of social development (Santrock, 1991), it would conclude that the client did not feel success often in her childhood. This view is based on her reluctance to talk about family issues; she would very quickly become timid and would verbally express that she did not want to talk right now, and also used such hesitation strategies as turning on her side while in bed or shortly crying one time.

The social work intern's observations were from both verbal and nonverbal client activities. The data obtained from Dianna indicates that she was adopted and the father was very nice, but one of the siblings was not such a nice person. When asked about her mother and the other family members, she described them briefly-"they're all right, but I don't know all of the family members, where they live..."and she could not go on for a long time.

The social work intern suspected that Dianna may have had significant psychological influences during her teenage years. That would include a lack of communication between family members, sensations of isolation, and a low self-esteem. Of the client's school years, she described herself as-"I didn't get much education as other people." According to her statement, she may have developed feelings of regret or frustration during her life, such as not being able to attend school. She also reported a 
substance abuse problem in which the client stated, "I drank beer three times a day, smoked me some cigarettes-two and a half packs a day." and during her teenage years until now she has spent her life at the mental health hospital. Dianna seemed very depressed; she was having a difficult time to find self-identity, lost in the confusion stage (Santrock, 1991).

The client was struggling with every relationship in her past. According to her statements she was supposedly married and had three children and they were all murdered. The client may have felt failure as a wife and mother. Likewise, she did not trust government because they did not help her find her children. This also was concerned that her beliefs were influenced from her delusional states.

\section{Client Strengths}

The client's personality was very independent, friendly with those close to her, and creative, such as she had a good ability to write a poem. These character traits express her resilient strength through her life. The social work intern noticed that the client had a very close friend at the group home, and seemed mentally supported from him, such as the fact that she write cards a couple of times during the sessions. As an added bonus, during those moments she became more willing to open up about her family issues. During the session, she seemed missed her family members, complaining about her sister not visiting her. However, the first time she did not seem to have any memory of her family, but rather she regained her memory and expressed her emotional feelings about them. It was concerned that either she was not trusting of any interviewer or that she actually could not remember. However, due to the client's sharing of her emotional feelings and her thoughts, the social work intern came to believe the former. Therefore, it would call that a positive building relationship between the social work intern and the client, involving thrust and a feeling of safety.

\section{Traumatic Events and Client Adaptation}

The client's discharge was planned, in light of a much-improved gait, progress in the areas of self-care and positive results to hospital medication. Also, her behavior was very positive, such as she was becoming more socialized, has cooperated with her day program, and strongly verbalized that she willing to return to the group home. The client had a strong desire to go back her day program, but at the same time she seemed very anxious about going back her placement. The bright side was that she also recognized that she needed to go back.

The dementia of mental illness, including the client's level of participation in hospital functions, was not likely to change quickly, especially in the elderly. They could have sensations of hopelessness and despair (Gitterman \& Shulman, 1994). Additionally, the client has a lack of any support system, causing more depression and isolation. That would influence her symptoms of weakness, as well as her feelings of depression. It is important to understand the support members are very critical in giving attention to mental illness clients.

\section{Ego Functions and Defenses}

The client has ego defenses, composed of overwhelming anxiety caused by her mental diagnosis. This was in operation since she was hospitalized. The client had so many painful memories, and some of them she remembered and the others she could not remember that would relate to her ego functioning. In the interview, she was confronting her anger and frustration about her placement in the different hospitals.

The client also uses denial as a defense against the strong negative stress of her situation. Sometimes, she could not find her room by herself that would fall under being legally blind or possibly dementia. She covered herself with the words "I'm not really good about directions and getting around places." On a positive note, she tried to make her own bed that would help her client's sense of independence and that belief could give her hope, a wish, and self-care (Kennedy, Lowe, Grey, \& Short, 1995). 
Dianna appeared to have a good sense of self-discrimination. The client felt very confident about the day program because she used to be a member for three years. Therefore, she knew very well about that sort of environment. Through the day program, she was trying to understand how she could best function in the environment. In addition, she was showing and explained about the day program, what she liked about it. She introduced her friends and the day program staff to the interviewer and said 'this is my friend and she will be with me.' It showed the clients' ability to accept others and growth self-confidence. The change in her mood influenced her to feel supported and encouraged by people around her. On the other hand, she felt anxiety and fear about being in the day program.

\section{Formulation}

While all of the changing environments in her work, she undergoes mental treatment through medication. She underlined feelings of depression that probably have been repressed since her teenage years. These feelings of depression could have been augmented by the hospitalization as well. Her relationships with family or ex-boyfriends were not satisfying, and were most likely painful and negative memories. The client often showed some depression symptoms and a lack social contact. That behavior encouraged failure with any relationship. However, if she would become actively involved the day program on a continuing basis, then that would provide her with the motivational sources and support system she needs to thrive. Also, at work was the idea that the loss of physical and mental abilities may reinforce her feelings of inadequacy and further helplessness.

\section{Working Agreement}

Dianna and interviewer have agreed that it will help her to be supported through her times of isolation, as well as with her dementia and gait improvement and delusional behavior. It was hope to assess Dianna in a way that it could connect her anxious feelings with her disability, and to help her begin to erase her losses. The study was explored with her what these losses mean for her. In this work with Dianna, it faced many mental and physical challenges.

\section{Psychodynamic Interventions \\ Client's History and Implications}

Dianna's feelings of isolation and mental illness often lead her to medical treatment. The hospital staff who work with the client reported that she was often timid and uncooperative while in treatment, had difficulty taking the initiative, and often stated that she "doesn't want to do" the test nurophysic test. This issues were carried over into the regular team meeting, members of which were working to help Dianna develop strategies to increase her level of hospital function.

The client's defenses and difficult feelings and experiences also affected the work with client. When the client was very cooperative, the worker mentioned to client about her defenses, and she has accepted that her behavior was inappropriate, and felt guilty about what she had done. She verbalized that if someone says she has to do something, then she does not want to do it. As a result, the approach have changed the strategy to a soft and gentle one when dealing with her, when it is needed to offer suggestions or other possible options that would challenge any of these points.

Through this case, it was important to learn and experience some counter-transference during a session in which client was beginning to share her past experience and painful memory regarding some loss and hopelessness. It felt sorry for her and even guilty for listening about what had been said, because her experience was very painful for her and for anyone, especially in light of the fact that, since she was a teenager, she has lived in a hospital setting (Epstenin \& Feiner, 1979).

\section{Corrective Emotional Responses}

This study often used empathic responses to reflect client's feelings, such as, "you seemed very depressed and frustrated about your experience" and "that must be very difficult to say, and think for 
being able to share that with anyone." Also, it was appropriated to use the empathic responses in which a person infer some meaning beyond what client wanted to hear, to give her the feeling she was being supported (Hepworth, Rooney, \& Larsen, 1997).

The study also utilized validation in working with client. For example, when client discussed her anger at her situation, such as "if I were you, I would be worse than you, probably." When she expressed her feelings related to the loss and hopelessness and her isolation, it mirrored, "you should not feel that way; that sounds very painful." In addition, the validation practice would be when the client said "I don't want to stay in the hospital now and I need fresh air." The response was "who would want to stay in the hospital especially in the fall, I understand what you mean."

Playful use of self within or between sessions to demonstrate caring, protection, availability, Carl Rogers (1958) refers to this as "unconditional positive regard" (Murphy \& Dillon, 1997, p.78). It was important to show warmth of caring to client, use a soft voice, and not use wild gestures. Moreover, the personal sharing between client and social worker has a benefit in the healing process that would be simply a part of human nature, applicable to anyone.

\section{CONCLUSION}

This study approached to assess and intervene a geriatric and psychiatric mental health hospital client based on a psychodynamic perspective. The psychodynamic approach suggest that older adults in the geriatric and psychiatric medical setting may have limitation to be fully effective. This case study further suggest that perceived barriers may differ for older and younger clients and also mild and severe mental illness clients, which may indicate the need for age-specific and diagnosis-specific social work assessment and intervention and also services targeted to mental health related aging populations.

\section{RERERENCES}

Beck, U. C. (2012). Psychodynamic coaching: Focus and depth. London: Karnac Books Ltd.

Epstein, L., \& Feiner, A.H. (1979). Countertransference: The therapist's contribution to treatment. In Boston University School of Social Work, Readings in clinical assessment and intervention (pp.97-118). New York: American Heritage.

Gitterman, A., \& Shulman, L. ( $2^{\text {nd }}$ Eds.). (1994). Mutual aid groups, vulnerable populations, and the life cycle. New York: Columbia University Press.

Hepworth, D. H., Rooney, R. H., \& Larsen, J.A. (Eds.). (1997). Direct social work practice: Theory and skills. Pacific Grove: Brooks/Cole.

Kennedy, P. Lowe, R., Grey, N., \& Short, E. (1995). Traumatic spinal cord injury and psychological impact: A cross-sectional analysis of coping strategies. British Journal of Clinical Psychology, 34, 627-639.

Murphy, B. C. \& Dillon, C. (4 ${ }^{\text {th }}$ Eds.). (1999). Interviewing in action in a multicultural world. Belmont, CA: Brooks/Cole, Cengage Learning, Inc.

Santrock, J. W. (3 ${ }^{\text {rd }}$ Eds.). (1991). Psychology: The science of mind and behavior. Dallas: Wm. C. Brown. 